\title{
Duration of untreated psychosis and need for admission in patients who engage with mental health services in the prodromal phase
}

Lucia R. Valmaggia, Majella Byrne, Fern Day, Matthew R. Broome, Louise Johns, Oliver Howes, Paddy Power, Steven Badger, Paolo Fusar-Poli and Philip K. McGuire

\section{Background}

It is unknown whether prodromal services improve outcomes in those who go on to develop psychosis, and whether these patients are demographically different from the overall first-episode population.

\section{Aims}

To compare sociodemographic features, duration of untreated psychosis, hospital admission and frequency of compulsory treatment in the first year after the onset of psychosis in patients who present to prodromal services with patients who did not present to services until the first episode of psychosis.

\section{Method}

We compared two groups of patients with first-episode psychosis: one who made transition after presenting in the prodromal phase and the other who had presented with a first episode.

\section{Results}

The patients who had presented before the first episode were more likely to be employed and less likely to belong to an ethnic minority group. They had a shorter duration of untreated psychosis, and were less likely to have been admitted to hospital and to have required compulsory treatment.

\section{Conclusions}

Patients who develop psychosis after being engaged in the prodromal phase have a better short-term clinical outcome than patients who do not present until the first episode. Patients who present during first episodes may be more likely to have sociodemographic features associated with relatively poor outcomes.

\section{Declaration of interest}

None.

\section{Copyright and usage}

(c) The Royal College of Psychiatrists 2015.
A key objective of early intervention services for psychosis is to reduce the period between the onset of frank psychosis and the initiation of its treatment, the duration of untreated psychosis (DUP). ${ }^{1}$ Early intervention services include teams that engage people who are at high risk of developing psychosis, and have an at risk mental state (ARMS). A substantial proportion (20-35\%) of those engaged at this stage will develop a first episode of psychosis within 3 years of presentation, ${ }^{2}$ mostly schizophrenia spectrum psychoses. ${ }^{3}$ Clinical services for ARMS closely monitor their clients for early signs of psychosis and may therefore be able to detect the onset of psychosis at a relatively early stage, This might be expected to minimise the interval between the onset of illness and the initiation of treatment, ${ }^{4}$ although the putative benefit of high risk services has yet be demonstrated. One aim of the present study was to address this issue by comparing the DUP in such patients with that in patients who did not present to services until the first episode of psychosis.

There is a robust relationship between the DUP and clinical outcomes in psychosis, with a shorter DUP associated with better clinical and functional outcomes. ${ }^{5}$ A related objective of the present study was to compare short-term clinical outcomes in these two groups, using frequency of hospital admission and frequency of compulsory treatment in the first year after the onset of psychosis as outcome measures.

Because people who present to clinical services for people with an ARMS are 'help-seeking', it is sometimes assumed that psychotic patients who were seen before the onset of illness may be unrepresentative of the overall patient population, and may have a relatively good prognosis. However, to our knowledge, the sociodemographic features of this group have never been compared to those of a general first-episode sample. The final aim of our study was to address this issue.
Our first hypothesis was that patients who had been engaged by services before the onset of psychosis would have a shorter DUP and better clinical outcomes than patients who had not been seen before the first episode. We then tested the hypothesis that the groups would differ on sociodemographic features that are thought to influence prognosis following the first episode.

\section{Method}

\section{Study design}

We compared the DUP, admissions rate and length of admission in people attending the Outreach and Support in South London Service (OASIS), a specialised community mental health service for people with an ARMS for psychosis ${ }^{6}$ with a first-episode sample that did not access help before becoming psychotic referred to the Lambeth Early Onset Crisis and Assessment Team (LEO-CAT). ${ }^{7}$ The LEO-CAT patients in the present study were assessed over a similar time period (2003-2005) to those whose first episode developed subsequent to management by OASIS (2002-2007).

\section{Patients who developed psychosis after presenting in the prodromal phase}

This group was drawn from 228 participants who had been recruited to OASIS and met the PACE criteria ${ }^{8}$ for an ARMS for psychosis. OASIS accepts self-referrals, and referrals from relatives and non-health agencies, as well as from health professionals, with most referrals coming from primary care. ${ }^{6}$ Most presented with attenuated psychotic symptoms alone $(n=159,70 \%)$. A smaller proportion had both attenuated symptoms and a trait risk factor $(n=27,12 \%)$, or attenuated symptoms plus a brief limited 
intermittent psychotic (BLIP) episode $(n=18,8 \%)$, or a BLIP alone $(n=21,9 \%)$. One participant $(0.4 \%)$ had a BLIP and a trait risk factor and one $(0.4 \%)$ reported attenuated symptoms, a trait risk factor and a BLIP; one was a missing value $(0.4 \%)$. Of this sample, 43 subsequently developed a first episode of psychosis, most of whom (33/43) did so within 2 years. The mean time between presentation to OASIS and the onset of psychosis was 563 days (s.d. $=721$ ), while the median was 345 days (25th and 75th percentiles $=135,714$ ).

The participants were regularly monitored for signs of frank psychosis for at least 2 years. They also received social and vocational support, psychological therapy and medication. Approximately $12 \%$ of patients disengage from the service. ${ }^{6}$ We recently carried out a follow-up study (median length of follow-up 4 years) and we were able to find information regarding current diagnosis and current use of services for all service users, including those who made a transition after disengaging with OASIS or after moving outside of the catchment area of the service. Among the OASIS service users who made a transition to psychosis, 10 individuals did so after the 2-year treatment window offered by OASIS.

If a participant developed frank psychosis, they were immediately referred to the local first-episode team (Lambeth Early Onset Service or Southwark Early Intervention Team ${ }^{7,9}$, which then assumed clinical responsibility for the patient. Both teams offer similar comprehensive care packages to first-episode patients. All clinical decisions about the management of the patient, thereafter, including whether treatment with antipsychotic medication was indicated, the timing of treatment initiation, and the type of medication used, were made by the early intervention team (independent of OASIS). The same applied to decisions about whether the patients should be managed in the community or required hospital admission, and whether compulsory treatment was necessary.

\section{Patients who did not present until the first episode of psychosis}

These patients $(n=147)$ were referred to a crisis and assessment team for patients with first-episode psychosis (the LEO-CAT), serving in the same geographical catchment area in South London as OASIS. ${ }^{7}$ The team was designed to detect and engage patients (16-35 years old) as soon after the onset of first-episode psychosis as possible. Patients who had previously contacted mental health services with prodromal symptoms were excluded. Like OASIS, LEO-CAT accepted self-referrals, and referrals made by health and non-health agencies. Referrals were usually seen within a few days of referral. The majority of these patients had been referred by secondary care services.

\section{Role of the funding source}

The OASIS service and the LEO-CAT team were supported by the Guy's and St Thomas' Charitable Foundation, by the Mental Health Foundation and by the South London and Maudsley NHS Trust. The funding sources had no role in the design, conduct or analysis of this study.

\section{Ethical approval}

The study received ethical approval by the ethical committee of the South London and Maudsley Trust (study approval number 195/02).

\section{Measures}

The ARMS was defined according to PACE criteria ${ }^{8}$ as assessed using the comprehensive assessment of the ARMS (CAARMS), ${ }^{10}$ which has excellent validity and reliability. ${ }^{11}$ The onset of psychosis in the OASIS group was defined prospectively, using the criteria for transition to psychosis in the CAARMS. ${ }^{11} \mathrm{~A}$ first-episode diagnosis of psychosis was made by a member of the clinical team and confirmed by the team psychiatrist. The diagnosis of firstepisode psychosis was confirmed by accessing the electronic clinical records of each patient after their transfer from OASIS to a local first-episode team. The electronic records were also used to define the date when antipsychotic treatment was initiated. All patients in the study (in both groups) were managed by the local health trust (South London And Maudsley NHS Trust) after the onset of psychosis, and all clinical information on the subjects was systematically recorded and stored on a single electronic database (Electronic Patient Journey System). The onset of psychosis in the LEO-CAT group was determined retrospectively, by a trained member of the clinical research team. In both groups, the DUP was defined as the time in days from the onset of psychosis to the start of treatment with antipsychotic medication.

Clinical outcomes in the 12 months following the first episode of psychosis were assessed by contacting each patients' responsible medical officer and by examining each patient's electronic patient record. These records also specified whether patients had been admitted to hospital, whether this involved use of the Mental Health Act, and the dates of admission and discharge for any stays in hospital.

\section{Statistical analyses}

Data were analysed using SPSS version 21. The Kruskal-Wallis non-parametric one-way analysis of variance and the MannWhitney $U$-test were used to examine the quantitative variables because the data were either not normally distributed or the sample size was small. Both one and two sample chi-square tests were used for categorical data.

\section{Results}

\section{Demographic differences between OASIS and LEO-CAT patients}

The two groups were similar in terms of age, gender and marital status, but patients who had not presented until their first episode were more likely to be unemployed and to belong to an ethnic minority group (Table 1). As expected patients who had presented in the prodromal phase were more likely to have been referred from primary care.

\section{Duration of untreated psychosis}

The mean DUP in patients who developed psychosis after being managed by OASIS was 11.2 days (s.d. $=12.2)$, while the median was 7 (25th and 75th Percentiles $=3,14$ ). The mean DUP for patients who presented with psychosis to LEO-CAT was 366.5 days (s.d. $=1041.1 ;$ median $=70 ; 25$ th and 75 th percentiles $=20,278)$ $(Z=-6.454, P \leqslant 0.000$; Table 2$)$.

\section{Admission to hospital within 1 year from transition}

Less than half (46\%) of the 43 patients who developed psychosis after management by OASIS were admitted to hospital by the first-episode team that they were referred to. Most $(14 ; 70 \%)$ were admitted voluntarily, with a minority $(6 ; 30 \%)$ admitted on a compulsory basis under the Mental Health Act. The mean 
Table 1 Demographic characteristics of ARMS patient who made a transition to psychosis and first-episode patients

\begin{tabular}{|c|c|c|c|c|c|}
\hline & \multirow{2}{*}{$\begin{array}{l}\text { ARMS transition } \\
\quad n=43\end{array}$} & \multirow{2}{*}{$\begin{array}{l}\text { First episode (LEO-CAT) } \\
\qquad n=147\end{array}$} & \multicolumn{3}{|c|}{ ARMT-transition versus first episode } \\
\hline & & & Test statistics & d.f. & $P$ \\
\hline \multicolumn{6}{|l|}{ Age } \\
\hline Mean (s.d.) & $23.7(4.8)$ & $24.1(5.7)$ & $t=-446$ & 188 & 0.656 \\
\hline \multicolumn{6}{|l|}{ Gender n (\%) } \\
\hline Male & $25(58.1)$ & $106(72.1)$ & $\chi^{2}=3.032$ & 1 & 0.082 \\
\hline Female & $18(41.9)$ & $41(27.9)$ & & & \\
\hline \multicolumn{6}{|l|}{ Ethnicity n (\%) } \\
\hline Black African-Caribbean & $18(41.9)$ & $81(55.1)$ & $\chi^{2}=12.07$ & 4 & 0.017 \\
\hline White British & $16(37.2)$ & $24(16.3)$ & & & \\
\hline White other & $3(7)$ & $19(12.9)$ & & & \\
\hline Other & $6(14)$ & $11(7.5)$ & & & \\
\hline Mixed & $0(0)$ & $12(8.2)$ & & & \\
\hline \multicolumn{6}{|l|}{ Marital status n (\%) } \\
\hline Single & $39(90.7)$ & $130(88.4)$ & $\chi^{2}=818$ & 2 & 0.664 \\
\hline Married or living together & $1(2.3)$ & $8(5.4)$ & & & \\
\hline Divorced or separated & $2(4.7)$ & $9(6.1)$ & & & \\
\hline Missing data & $1(2.3)$ & $0(0)$ & & & \\
\hline \multicolumn{6}{|l|}{ Employment n (\%) } \\
\hline Student & $13(30.2)$ & $11(7.5)$ & $\chi^{2}=20.489$ & 2 & $<0.000$ \\
\hline Employed & $10(23.3)$ & $20(13.6)$ & & & \\
\hline Unemployed & $19(44.2)$ & $112(76.2)$ & & & \\
\hline Missing data & $1(2.3)$ & $4(2.7)$ & & & \\
\hline \multicolumn{6}{|l|}{ Referrer n (\%) } \\
\hline Total primary care & $15(34.9)$ & $13(8.9)$ & $\chi^{2}=17.954$ & 1 & $<0.000$ \\
\hline GP practice & $10(23.3)$ & $10(6.8)$ & & & \\
\hline College or school & $4(9.3)$ & $0(0)$ & & & \\
\hline Relative & $0(0)$ & $1(0.7)$ & & & \\
\hline Self-referred & $1(2.3)$ & $2(1.4)$ & & & \\
\hline Total secondary care & $28(65.1)$ & $134(91.1)$ & & & \\
\hline Community mental health team & $11(25.6)$ & $56(38.1)$ & & & \\
\hline A\&E & $3(7)$ & $10(6.8)$ & & & \\
\hline Other & $5(11.6)$ & $10(6.8)$ & & & \\
\hline First-episode team & $9(20.9)$ & $\begin{array}{c}46 \text { (31.2) } \\
\text { Inpatient unit }\end{array}$ & & & \\
\hline OASIS & $\mathrm{n} / \mathrm{a}$ & $12^{\mathrm{a}}(8.2)$ & & & \\
\hline
\end{tabular}

duration of admission was 60.9 days (s.d. $=61.6$; median $=34$; 25th and 75th percentiles $=29,79$ ).

By contrast, $100(68 \%)$ of the 147 patients seen by LEO-CAT were admitted to hospital, and in most cases $(74,74 \%)$ this was compulsory admission under the Mental Health Act. The mean length of stay in hospital was 79.7 days (s.d. $=72.9$; median 56 ; 25th and 75th percentiles $=32,101$ ).

Compared to those treated by LEO-CAT, the patients who originally presented to OASIS were less likely to require hospital admission $\left(\chi^{2}=6.619 ;\right.$ d.f. $\left.=1 ; P=0.010\right)$ and less likely to be admitted under the Mental Health Act $\left(\chi^{2}=6.950\right.$; d.f. $=1$; $P \leqslant 0.008)$. The group differences in the duration of hospital admissions were not significant $(z=-1.476 ; P=0.140)$.

With regard to the effect of employment status at baseline and length of admission, the results showed no effect of employment status on length of admission in both groups (OASIS: $\chi^{2}=1.899$, d.f. $=2, P<0.387$; LEO: $\chi^{2}=6.607$, d.f. $=3, P<0.086$ ).

\section{Discussion}

This study explored whether there was a difference in DUP and admission rates between patients who engaged in treatment during the prodromal stage and subsequently developed psychosis and patients whose initial contact with mental health services was at the time of the first episode of psychosis. In line with our first hypothesis, the DUP in the prodromal group was much shorter than in those who presented with a first episode: on average 11 days, as opposed to approximately 1 year. Patients who presented in the prodromal stage were less likely to require admission following the onset of psychosis and less likely to require a compulsory admission.

The marked difference in DUP is particularly notable because LEO-CAT was a specialised team designed to detect first-episode

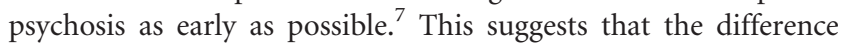
is not attributable to a lack of awareness of the need for the early initiation of treatment in the comparison service. Indeed the DUP in the LEO-CAT group is comparable to that reported in other studies from the same geographical area (10.5 months; ${ }^{12} 12$ months $\left.s^{13}\right)$, from other parts of the UK $\left(9\right.$ months $\left.{ }^{14}\right)$, and internationally $\left(12-24\right.$ months $\left.{ }^{15}\right)$. We predicted that the DUP in people who were initially managed by a high risk service would be relative short because one of the main aims of clinical management at this stage is to closely monitor the first signs of psychosis. Moreover, people with an ARMS are relatively insightful and help-seeking, and show high levels of engagement with high risk services. ${ }^{16,17}$ As a result they are generally likely to report changes in their mental state to the clinicians who are working with them. Once the onset of psychosis has been detected, the typically close working relationship between high risk services and local teams for patients with first-episode psychosis facilitates the rapid transfer of patients to the most appropriate service for the initiation of antipsychotic treatment. 
Table 2 DUP and admissions of ARMS patients who made a transition to psychosis and first-episode patients

\begin{tabular}{|c|c|c|c|c|}
\hline & \multirow{2}{*}{$\begin{array}{c}\text { ARMS+ } \\
n=43\end{array}$} & \multirow{2}{*}{$\begin{array}{c}\text { FEP } \\
n=147\end{array}$} & \multicolumn{2}{|c|}{ Statistical significance } \\
\hline & & & Test statistics & $P$ \\
\hline \multicolumn{5}{|l|}{ Duration of untreated psychosis } \\
\hline Mean in days (s.d.) & $11.2(12.2)$ & $366.5(1041.1)$ & $Z=-6.454$ & $<0.000$ \\
\hline Median in days (25th and 75th Percentiles) & $7(3,14)$ & $70(20,278)$ & & \\
\hline \multicolumn{5}{|l|}{ Admission to hospital } \\
\hline & $\begin{array}{c}\text { ARMS+requiring admission } \\
\qquad n=20 n(\%)\end{array}$ & $\begin{array}{l}\text { FEP requiring admission } \\
\qquad n=100 n(\%)\end{array}$ & & \\
\hline Admission & $20(46)$ & $100(68)$ & $\chi^{2}=6.619$ d.f. $=1$ & 0.010 \\
\hline Voluntary admission & $14(70)$ & $38(38)$ & $\chi^{2}=6.950$, d.f. $=1$ & 0.008 \\
\hline Involuntary admission & $6(30)$ & $62(62)$ & & \\
\hline \multicolumn{5}{|l|}{ Length of stay in hospital } \\
\hline Mean in days (s.d.) & $60.9(61.6)$ & 79.7 (72.9) & $z=-1.476$ & 0.140 \\
\hline Median in days (25th and 75 th percentiles) & $34(29 ; 79)$ & $56(32 ; 101)$ & & \\
\hline Length of stay in hospital by type of admission & $\begin{array}{l}\text { ARMS+voluntary admission } \\
\qquad n=14\end{array}$ & $\begin{array}{l}\text { FEP voluntary admission } \\
\qquad n=38\end{array}$ & & \\
\hline Mean in days (s.d.) & $46.8(29.3)$ & $50.4(40.0)$ & $Z=-0.126$ & 0.900 \\
\hline \multirow[t]{2}{*}{ Median in days (25th and 75th percentiles) } & $30(29 ; 76)$ & $34(15 ; 86)$ & & \\
\hline & $\begin{array}{c}\text { ARMS+involuntary admission } \\
n=6\end{array}$ & $\begin{array}{l}\text { FEP involuntary admission } \\
\qquad n=62\end{array}$ & & \\
\hline Mean in days (s.d.) & $100.6(107.8)$ & $96.9(81.6)$ & $z=-0.453$ & 0.650 \\
\hline Median in days (25th and 75 th percentiles) & $79(27 ; 185)$ & $70(42 ; 119)$ & & \\
\hline
\end{tabular}

Reducing the DUP is a central objective of early intervention in psychosis $^{12}$ as there is a robust association between its length and subsequent clinical outcome with a shorter DUP being linked to a better prognosis. ${ }^{18}$ However, whether a shorter DUP leads to a better clinical outcome or a short DUP is a feature of a subgroup of patients who are more likely to have a good outcome (or both) remains unclear. One way of resolving this issue is to examine the effect of clinical interventions that reduce the DUP on clinical outcomes. In the present study, we found that the outcome in the first year after engagement with a first-episode team was better in the patients who had first been engaged in the prodromal phase: they were less likely to be admitted to hospital and less likely to require a compulsory admission. This better outcome may have resulted from engagement with services in the prodromal phase and a shorter DUP. A recent study in Norway found in first-episode patients receiving early intervention that a shorter DUP was associated with fewer inpatient admissions at 2 -year follow-up ${ }^{19}$ and higher recovery rates at 10 years. ${ }^{5}$

However, it is also possible that people who present to high risk services before the onset of psychosis represent a subgroup of the first-episode population with a relatively good prognosis. In the present study, the two groups were similar in age, gender and marital status. The patients who had first presented to a high risk service were more likely to have been referred from primary care. However, in this case it probably reflects the fact that primary care is the main source of referrals of people with an ARMS. ${ }^{6}$ Similarly, being employed is a good prognostic factor in firstepisode patients, but the higher levels of employment in the group who first presented in the prodrome might simply be related to them presenting to services at an earlier stage of the disorder: the prodromal phase is when many patients with psychosis first become unemployed. ${ }^{4}$

Although the OASIS group reported better functioning, it is theoretically possible that having a psychosis prodrome is associated with a worse prognosis. Previous findings have shown that longer length of stay in hospital at admission in individuals who presents with an 'acute onset' are associated with a poorer outcome. $^{20}$ However, while we found that individuals who engaged in the prodromal stage were less likely to be admitted to hospital and less likely to require the use of compulsory admission, no difference was found between the two groups in length of admission. Furthermore, in both groups, voluntary admission was associated with a shorter length of stay in hospital.

The local population in the catchment area of both OASIS and LEO-CAT has a high proportion of people from ethnic minorities and a very high incidence of psychosis, especially in those from Black ethnic minorities. ${ }^{21}$ Among those managed by OASIS, although there was a higher rate of people from Black minority ethnic groups compared to the general population rates for the same area (22\% according to the 2011 census), there were no significant differences between ethnic groups in the risk of transition to psychosis, hospital admission and use of the Mental Health Act. The patients who first presented to high risk services were less likely to belong to an ethnic minority than those who presented at the first episode. The relationship between ethnicity and outcomes in psychosis is controversial, with some studies suggesting that it was relatively good in minority groups, ${ }^{22}$ but other found the opposite. ${ }^{23}$ The DUP in first-episode patients, which is usually related to clinical outcome, has not been found to differ between ethnic groups. ${ }^{13,22,24}$ It is thus difficult to know whether the better clinical outcomes observed in the OASIS group in the present study were a result of the lower proportion of patients from minority groups.

Our results seem to indicate that early detection services like OASIS may have lower efficacy in socially deprived areas. Indeed, our recent work in an inner London prison identified a large number of individuals experiencing ARMS and early psychosis who in the community were not help-seeking and had not been detected by conventional health services. ${ }^{25}$ Furthermore, a recent study analysing the 10-year outcome of first-episode patients found that social exclusion is present before the onset of the first episode and that it is still poor for the majority of cases at 10-year follow-up. ${ }^{26}$

\section{Limitations}

Patients who presented in the prodrome were ascertained from a clinical service that is limited to people who are help-seeking, whereas there was no such restriction on the comparison group that it is possible that the group differences in DUP and clinical 
outcome were related to the sampling of a subgroup of firstepisode patients with a relatively good prognosis. However, even if this were the case, the data suggest that high risk services provide a means of improving clinical outcomes in patients who present before the onset of psychosis. A further limitation is the lack of data regarding the use of illegal substances; however, in a recent study looking at the use of cannabis in ARMS, we found that lifetime cannabis use was common but not related to transition to psychosis. However, we did find that in the ARMS who used cannabis frequent use, early-onset use and continued use after clinical presentation were associated with transition to psychosis. ${ }^{27}$ A final limitation to the study was that in the firstepisode sample no data were available regarding the psychosis prodrome. Future studies should ascertain how many of the individuals presenting directly to the first episode psychosis service actually have a psychosis prodrome and compare those with people service users presenting during the ARMS stage.

\section{Clinical implications}

The benefits of clinical services for people at high risk for psychosis are usually conceptualised in terms of reducing the risk of psychosis, and ameliorating the presenting symptoms and social and vocational dysfunction. A further benefit may be that these services provide a very effective way of detecting the first signs of psychosis and minimising the interval between the onset of illness and the initiation of treatment.

Lucia R. Valmaggia, MSC, PhD, Majella Byrne, PhD, DClinPsych, King's College London, Institute of Psychiatry, London and Outreach and Support in South London South London and Maudsley NHS Foundation Trust, London; Fern Day, PhD, King's College London, Institute of Psychiatry, London; Matthew R Broome, MD, PhD, Department of Psychiatry, University of Oxford, London; Louise Johns, PhD,

DClinPsych, Oliver Howes, MD, PhD, King's College London, Institute of Psychiatry, London; Paddy Power, MD, MRCPsych, St Patrick's Mental Health Services, Dublin Ireland; Steven Badger, Outreach and Support in South London, South London and Maudsley NHS Foundation Trust, London; Paolo Fusar-Poli, MD, PhD, Philip K McGuire, MD, PhD, King's College London, Institute of Psychiatry, London and Outreach and Support in South London, South London and Maudsley NHS Foundation Trust, London, UK

Correspondence: Lucia Valmaggia, King's College London, Institute of Psychiatry (PO 77), De Crespigny Park, London SE5 8AF, UK. Email: lucia.valmaggia@kcl.ac.uk

First received 25 Apr 2014, final revision 9 Dec 2014, accepted 19 Dec 2014

\section{Acknowledgements}

Our special thanks go to the staff and service users of OASIS and LEO-CAT.

\section{Funding}

The authors acknowledge financial support from the National Institute for Health Research (NIHR) Biomedical Research Centre for Mental Health at South London and Maudsley NHS Foundation Trust and King's college London. The views expressed are those of the authors and not necessarily those of the NHS, the NIHR or the Department of Health.

\section{References}

1 NICE. Psychosis and Schizophrenia in Children and Young People. Recognition and Management. The British Psychological Society and The Royal College of Psychiatrists, 2013.

2 Fusar-Poli P, Bonoldi I, Yung AR, Borgwardt S, Kempton MJ, Valmaggia L, et al. Predicting psychosis: meta-analysis of transition outcomes in individuals at high clinical risk. Arch Gen Psychiatry 2012; 69: 220-9.

3 Fusar-Poli P, Bechdolf A, Taylor MJ, Bonoldi I, Carpenter WT, Yung AR, et al. At risk for schizophrenic or affective psychoses? A meta-analysis of DSM/ICD diagnostic outcomes in individuals at high clinical risk. Schizophr Bull 2013; 39: 923-32.

4 Valmaggia LR, McCrone P, Knapp M, Woolley JB, Broome MR, Tabraham P, et al. Economic impact of early intervention in people at high risk of psychosis. Psychol Med 2009; 39: 1617-26.
5 Hegelstad WT, Larsen TK, Auestad B, Evensen J, Haahr U, Joa I, et al. Longterm follow-up of the TIPS early detection in psychosis study: effects on 10year outcome. Am J Psychiatry 2012; 169: 374-80.

6 Fusar-Poli P, Byrne M, Badger S, Valmaggia LR, McGuire PK. Outreach and support in south London (OASIS), 2001-2011: ten years of early diagnosis and treatment for young individuals at high clinical risk for psychosis. Eur Psychiatry J Assoc Eur Psychiatrists 2013; 28: 315-26.

7 Power $\mathrm{P}$, McGuire $\mathrm{P}$, lacoponi E, Garety P, Morris E, Valmaggia L, et al. Lambeth early onset (LEO) and outreach \& support in south London (OASIS) service. Early Interv Psychia 2007; 1: 97-103.

8 Yung AR, Phillips LJ, McGorry PD, McFarlane CA, Francey S, Harrigan S, et al. Prediction of psychosis. A step towards indicated prevention of schizophrenia. Br J Psychiatry Suppl 1998; 172: 14-20.

9 Reynolds N, Wuyts P, Badger S, Fusar-Poli P, McGuire P, Valmaggia L. The impact of delivering GP training on the clinical high risk and first-episode psychosis on referrals and pathways to care. Early Interv Psychiatry 2014; doi: 10.1111/eip.12126.

10 Phillips L, Yung AR, McGorry PD. Identification of young people at risk of psychosis: validation of personal assessment and crisis evaluation clinic intake criteria. Aust N Z J Psychiatry 2000; 34: S164-9.

11 Yung AR, Yuen HP, McGorry PD, Phillips LJ, Kelly D, Dell'Olio M, et al. Mapping the onset of psychosis: the comprehensive assessment of at-risk mental states. Aust N Z J Psychiatry 2005; 39: 964-71.

12 Craig TK, Garety P, Power P, Rahaman N, Colbert S, Fornells-Ambrojo M, et al. The Lambeth Early Onset (LEO) Team: randomised controlled trial of the effectiveness of specialised care for early psychosis. BMJ 2004; 329: 1067.

13 Morgan C, Fearon P, Hutchinson G, McKenzie K, Lappin JM, Abdul-Al R, et al. Duration of untreated psychosis and ethnicity in the AESOP first-onset psychosis study. Psychol Med 2006; 36: 239-47.

14 Drake RJ, Haley CJ, Akhtar S, Lewis SW. Causes and consequences of duration of untreated psychosis in schizophrenia. Br J Psychiatry 2000; 177 $511-5$.

15 Norman RM, Townsend L, Malla AK. Duration of untreated psychosis and cognitive functioning in first-episode patients. Br J Psychiatry 2001; 179: 340-5.

16 Green CE, McGuire PK, Ashworth M, Valmaggia LR. Outreach and support in south London (OASIS). Outcomes of non-attenders to a service for people at high risk of psychosis: the case for a more assertive approach to assessment. Psychol Med 2011; 41: 243-50.

17 Lappin JM, Morgan KD, Valmaggia LR, Broome MR, Woolley JB, Johns LC, et al. Insight in individuals with an at risk mental state. Schizophr Res 2007; 90 : $238-44$

18 Marshall $M$, Lewis S, Lockwood A, Drake R, Jones $P$, Croudace $T$. Association between duration of untreated psychosis and outcome in cohorts of first-episode patients: a systematic review. Arch Gen Psychiatry 2005; 62: 975-83.

19 Melle I, Larsen TK, Haahr U, Friis S, Johannesen JO, Opjordsmoen S, et al. Prevention of negative symptom psychopathologies in first-episode schizophrenia: two-year effects of reducing the duration of untreated psychosis. Arch Gen Psychiatry 2008; 65: 634-40.

20 Queirazza F, Semple DM, Lawrie SM. Transition to schizophrenia in acute and transient psychotic disorders. Br J Psychiatry 2014; 204: 299-305.

21 Fearon $\mathrm{P}$, Kirkbride JB, Morgan C, Dazzan P, Morgan K, Lloyd T, et al. Incidence of schizophrenia and other psychoses in ethnic minority groups: results from the MRC AESOP study. Psychol Med 2006; 36: 1541-50.

22 Chorlton E, McKenzie K, Morgan C, Doody G. Course and outcome of psychosis in black Caribbean populations and other ethnic groups living in the UK: a systematic review. Int J Social Psychiatry 2012; 58: 400-8.

23 Morgan C, Lappin J, Heslin M, Croudace T, Doody G, Donoghue K, et al. Ethnicity, social disadvantage and the long-term course and outcome of psychosis. Schzophr Res 2014; 153: S348.

24 Anderson KK, Flora N, Archie S, Morgan C, McKenzie K. A meta-analysis of ethnic differences in pathways to care at the first episode of psychosis. Acta Psychiatrica Scand 2014; 130: 257-68.

25 Jarrett M, Craig T, Parrott J, Forrester A, Winton-Brown T, Maguire H, et al. Identifying men at ultra high risk of psychosis in a prison population. Schizophr Res 2012; 136: 1-6.

26 Morgan C, Lappin J, Heslin M, Donoghue K, Lomas B, Reininghaus U, et al. Reappraising the long-term course and outcome of psychotic disorders: the AESOP-10 study. Psychol Med 2014; 44: 1-14.

27 Valmaggia LR, Day FL, Jones C, Bissoli S, Pugh C, Hall D, et al. Cannabis use and transition to psychosis in people at ultra-high risk. Psychol Med 2014; 44: 2503-12. 